\title{
Pain relief as a primary treatment goal: At what point does functioning and well-being become more important? A case study of an adolescent with debilitating chronic pain
}

\author{
Andrew S Tseng BA/BS ${ }^{1}$, Karen Weiss $\mathrm{PhD}^{2}$, Tracy Harrison $\mathrm{MD}^{2}$, Dan Hansen $\mathrm{RN}^{2}$, Barbara Bruce $\mathrm{PhD}^{2}$
}

\begin{abstract}
AS Tseng, K Weiss, T Harrison, D Hansen, B Bruce. Pain relief as a primary treatment goal: At what point does functioning and wellbeing become more important? A case study of an adolescent with debilitating chronic pain. Pain Res Manag 2014;19(4):219-223.
\end{abstract}

BACKGROUND: Pediatric chronic pain is a common problem with significant economic implications and devastating consequences on quality of life. The present report describes a case involving a 15-year-old girl with severe and debilitating chronic pain.

RESULTS: Before her referral to a pain rehabilitation program, the patient saw numerous specialists who treated her with an aggressive medical regimen and two spinal cord stimulators. She was then referred for intensive interdisciplinary treatment and, after three weeks of rehabilitation, she reported clinically significant changes in anxiety, pain catastrophizing and functional disability. The patient was successfully titrated off all of her opioid medications and, eventually, both neurostimulator implants were removed.

DISCUSSION: Interdisciplinary pain rehabilitation is a useful treatment for patients with chronic pain. With its primary emphasis on functional restoration as opposed to strictly pain reduction, patients can regain a higher quality of life with reduced pain and fewer medications, surgeries and hospitalizations.

Key Words: Behavioural therapy; Chronic pain; Pain rehabilitation

$\mathrm{D}$ espite an abundance of research investigating treatment for chronic pain conditions, chronic pain continues to be a common problem in adult and pediatric populations. Patients with chronic pain often do not achieve substantial relief from a number of medical and nonmedical interventions, and their struggles with pain continue to have a significant effect on quality of life (1). Patients and providers go to great lengths to achieve pain reduction through the use of multiple medications, physical therapy, integrative medicine and medical procedures including surgeries. As a result of extended medical evaluation and treatment, delayed referral to interdisciplinary treatment, employment difficulties, disability and economic burden occur $(2,3)$. Some patients will spend many years searching for additional explanations for the etiology of their pain, and treatments to decrease and/or resolve their pain $(4,5)$.

It is well established that chronic pain is a biopsychosocial phenomenon (6). Nonetheless, many patients continue to receive only medical treatments for their chronic pain, without consideration for the psychosocial factors that are likely contributing to pain and disability. This sort of singular approach is not only minimally effective, but may also lead to increased disability and decreased psychological well-being.

Chronic pain may be particularly devastating for children and adolescents. Many pediatric patients with chronic pain experience reduced functioning and are believed to have a quality of life lower
Le soulagement de la douleur comme premier objectif thérapeutique : quand le fonctionnement et le bien-être prennent-ils plus d'importance? L'étude de cas d'une adolescente souffrant de douleur chronique débilitante

HISTORIQUE : La douleur chronique est un problème courant en pédiatrie, aux répercussions économiques importantes et aux conséquences dévastatrices sur la qualité de vie. Le présent rapport décrit le cas d'une fille de 15 ans atteinte de grave douleur chronique et débilitante.

RÉSULTATS : Avant d'être aiguillée vers un programme de réadaptation de la douleur, la patiente a consulté de nombreux spécialistes qui l'ont traitée au moyen d'un traitement médical énergique et de deux stimulateurs de la moelle épinière. Elle a ensuite été orientée vers un traitement interdisciplinaire intensif et, au bout de trois semaines de réadaptation, a affirmé remarquer des changements substantiels sur le plan de l'anxiété, de la catastrophisation de la douleur et de l'incapacité fonctionnelle. Elle a été graduellement sevrée de tous ses médicaments opioïdes et s'est finalement fait retirer les deux neurostimulateurs qui lui avaient été implantés.

EXPOSÉ : La réadaptation interdisciplinaire de la douleur est un traitement utile pour les patients atteints de douleur chronique. Recherchant d'abord le rétablissement fonctionnel plutôt qu'une seule réduction de la douleur, les patients retrouvent une meilleure qualité de vie, ressentent moins de douleur, prennent moins de médicaments et subissent moins d'opérations et d'hospitalisations.

than that of cancer patients $(4,7)$. For patients with chronic pain having no apparent physical etiology, the response to medication and therapy is often poor (8). Debilitating chronic pain in adolescents has been associated with family dysfunction and emotional struggles. Pediatric patients often withdraw from school for prolonged periods of time, during which they not only fall behind in academics but also miss important social interactions $(1,7)$. This can lead to disruptions in development, particularly in the areas of social and emotional functioning.

The purpose of the present case study is to describe an adolescent girl who struggled with significant difficulties with chronic pain to highlight the negative consequences aggressive pain management treatment can have on a patient's functioning and well-being. We also discuss the utility of nonpharmacological pain rehabilitation management and the importance of considering all aspects of a patient's functioning, rather than pain relief being the only treatment outcome goal for pediatric pain patients.

Presenting problem

\section{CASE PRESENTATION}

Andrea (not patient's real name) was a 15-year-old girl who had developed severe bilateral pain of her upper and lower extremities, as well as facial pain with transient erythema over 22 months, all of which had begun as pain and redness in her left second toe.

\footnotetext{
${ }^{1}$ Mayo Medical School; 2Mayo Clinic Pain Rehabilitation Center, Rochester, Minnesota, USA

Correspondence: Mr Andrew Tseng, 200 First Street Southwest, Rochester, Minnesota 55901, USA. Telephone 480-276-5998,
}

fax 507-284-3933, e-mail tseng.andrew@mayo.edu 
TABLE 1

Medications patient was taking at four time points

\begin{tabular}{|c|c|c|c|}
\hline \multirow[b]{2}{*}{ Admission } & \multirow[b]{2}{*}{ Discharge } & \multicolumn{2}{|c|}{ Follow-up } \\
\hline & & Three months & Six months \\
\hline $\begin{array}{l}\text { Zolpidem } 12.5 \mathrm{mg} \\
\text { once daily }\end{array}$ & $\begin{array}{l}\text { Duloxetine } 60 \mathrm{mg} \\
\text { once daily }\end{array}$ & None & $\begin{array}{l}\text { Trazadone } 50 \\
\text { mg once daily }\end{array}$ \\
\hline $\begin{array}{l}\text { Duloxetine } 60 \mathrm{mg} \\
\text { once daily }\end{array}$ & $\begin{array}{l}\text { Pantoprazole } 40 \\
\text { mg once daily }\end{array}$ & & \\
\hline $\begin{array}{l}\text { Pregabalin } 150 \mathrm{mg} \\
\text { once daily }\end{array}$ & $\begin{array}{l}\text { Trazadone } 50 \mathrm{mg} \\
\text { once daily }\end{array}$ & & \\
\hline $\begin{array}{l}\text { Tapentadol } 100 \mathrm{mg} \\
\text { every } 4 \mathrm{~h}\end{array}$ & $\begin{array}{l}\text { Melatonin } 0.5 \mathrm{mg} \\
\text { once daily }\end{array}$ & & \\
\hline \multicolumn{4}{|l|}{$\begin{array}{l}\text { Pantoprazole } 40 \mathrm{mg} \\
\text { once daily }\end{array}$} \\
\hline \multicolumn{4}{|l|}{$\begin{array}{l}\text { Medroxyprogesterone } \\
10 \mathrm{mg} \text { once daily }\end{array}$} \\
\hline \multicolumn{4}{|l|}{$\begin{array}{l}\text { Topiramate } 25 \mathrm{mg} \\
\text { three times daily }\end{array}$} \\
\hline \multicolumn{4}{|l|}{$\begin{array}{l}\text { Ondansetron } 8 \mathrm{mg} \\
\text { three times daily }\end{array}$} \\
\hline \multicolumn{4}{|l|}{$\begin{array}{l}\text { Baclofen } 20 \mathrm{mg} \text { twice } \\
\text { daily }\end{array}$} \\
\hline \multicolumn{4}{|l|}{$\begin{array}{l}\text { Cephalexin } 500 \mathrm{mg} \\
\text { four times daily }\end{array}$} \\
\hline \multicolumn{4}{|l|}{$\begin{array}{l}\text { Fentanyl patch } 50 \mu \mathrm{g} / \mathrm{h} \\
\text { every three days }\end{array}$} \\
\hline \multicolumn{4}{|l|}{$\begin{array}{l}\text { Oxycodone } 10 \mathrm{mg} \\
\text { every } 6 \mathrm{~h}\end{array}$} \\
\hline \multicolumn{4}{|l|}{$\begin{array}{l}\text { Temazepam } 7.5 \mathrm{mg} \\
\text { every } 6 \mathrm{~h}\end{array}$} \\
\hline \multicolumn{4}{|l|}{$\begin{array}{l}\text { Trazadone } 100 \mathrm{mg} \\
\text { twice daily }\end{array}$} \\
\hline $\begin{array}{l}\text { Cyancobalamin } \\
\text { injections } 1000 \mu \mathrm{g} / \mathrm{mL} \\
\text { every two weeks }\end{array}$ & & & \\
\hline
\end{tabular}

\section{Developmental and medical history}

Andrea grew up in a household with two parents and two younger siblings (a brother and a sister). Her father worked for the government and her mother worked from home. She described her family situation as being comfortable and supportive, with no history of abuse. Before the onset of her pain, Andrea had started public high school after being home-schooled for four years. She was an honors student who earned mostly As. She was involved in many activities, including piano, flute, guitar and soccer. She believed that she made friends easily and had a few close confidants who were very supportive of her.

Andrea was reportedly healthy until she began noticing redness and pain in her left second toe while playing soccer at the age of 14 years. Within days, she noticed further discolouration and swelling that worsened over the next three months. At that time, Andrea refused to wear shoes, even in the winter snow, because of this pain. She and her parents sought care at an academic medical centre, where the differential diagnoses included Raynaud's phenomenon, erythromelalgia and reflex sympathetic dystrophy. Additional medical evaluation at other facilities was inconclusive.

Through the course of her symptomatology, Andrea had been evaluated and treated by numerous medical specialists and prescribed many different pain medications. Although the exact details of timing and dosage medication history were not available for the present manuscript, the patient's mother reported Andrea was first prescribed methadone, tramadol and gabapentin by a pain specialist who worked in conjunction with a health care provider who practiced 'holistic medicine', which mostly consisted of supplemental vitamins. When those medications were not effective, she tried (in succession) hydromorphone, hydrocodone, oxycodone and oxycontin. When these medications did not resolve the pain, she tried tapentadol and pregabalin (combined). Eventually, she added fentanyl patches.

In addition to medication management, Andrea also participated in physical therapy in the form of water aerobics three times per week and equine therapy as well, both for approximately three months. Despite these treatments, Andrea was unable to find a resolution of her pain. After approximately 18 months, Andrea also underwent implantation of a lumbar spinal cord stimulator followed a few months later by a cervical spinal cord stimulator. She experienced minimal improvement in pain, and was subsequently prescribed other medications including multiple opioids to treat her ongoing pain. Her final medication regimen when starting the interdisciplinary treatment program is presented in Table 1.

During the course of her illness and treatment, Andrea developed debilitating fatigue and depression with occasional thoughts of suicide. She spoke of losing friends because of her diminished ability to participate in social functions, and had become a victim of bullying due to her symptoms. Furthermore, she had gained 35 pounds $(15.75 \mathrm{~kg})$ and developed difficulties with urination and defecation, issues possibly associated with her medications and other lifestyle changes (eg, increase in sedentary behaviour). She was only able to pass stools during sleep when her body was sufficiently relaxed, resulting in frequent soiling of her bed, which her mother would have to clean. As the pain progressed, she became bedridden, and her mother quit her job to become her primary home caretaker. Andrea progressively became more disabled and eventually was unable to perform basic activities of daily living due to her pain. Subsequently, her mother became more involved in caring for these basic needs, including bathing her. This regression in autonomy caused some strain on their relationship, which was also distressing to Andrea. Despite the development of significant psychosocial concerns, Andrea was never referred to a psychologist or cognitive behavioural therapist.

\section{Initial presentation and behavioural conceptualization}

Andrea came to the Mayo Clinic (Rochester, Minnesota, USA) for an additional opinion for her multiple pain issues as well as urinary and defecation complaints, multiple food sensitivities and tachycardia. She saw providers in neurology, sleep medicine, dermatology, pediatric pain medicine, adolescent psychology and psychiatry, and underwent electromyography, polysomnography and autonomic reflex screening while at the institution. Numerous physicians became highly concerned with her extensive medication list, particularly given that she was frequently drowsy during visits with physicians and often fell asleep during interviews.

Andrea's treatment team determined she was struggling with a chronic pain condition and given that multiple treatments had not provided long-term relief and her functioning was severely impaired, she was referred to the Pediatric Pain Rehabilitation Program at the Mayo Clinic.

\section{Measurement of treatment outcomes}

As part of standard clinical practice, Andrea completed several measures before and on discharge from the pain program, in addition to three and six months following the program. These measures included functional disability because this is the primary treatment goal of the pain program; pain catastrophizing, depression and anxiety because all of these variables can influence pain and disability; and pain intensity.

Andrea completed the Functional Disability Inventory (FDI) (9), a well-established, 15-item, self-report measure that assesses difficulty in physical and psychosocial functioning due to health status. On this form, she rated the difficulties in engaging in activities of daily living with regard to home, school and social tasks on a five-point scale ranging from 0 (no trouble) to 4 (impossible). FDI scores range between 
0 and 60 , with 0 to $12=$ none or minimal, 13 to $20=$ mild, 21 to $29=$ moderate, and $>29=$ severe functional disability (10). The FDI has good reliability, including test-retest reliability (11), and appears to be a valid measure of functional disability in pediatric patients with chronic pain $(10,12)$.

Andrea completed the Pain Catastrophizing Scale for Children (13), a 13-item self-report questionnaire that measures exaggerated negative cognitions about anticipated or actual pain experiences. Responses range from 0 (not at all) to 4 (extremely). Total scores range from 0 to 52 with high scores indicating greater catastrophizing. The Pain Catastrophizing Scale for Children has been shown to be reliable and valid for children and adolescents $(13,14)$.

Andrea also completed The Center for Epidemiological Studies Depression Scale for Children, a self-report measure of depressive symptoms with acceptable reliability and validity for adolescents (1517). She rated depressive symptoms on a four-point scale ranging from 0 (not at all) to 3 (a lot). Total scores range from 0 to 60 , with higher scores suggesting more frequent and severe depressive symptoms. General guidelines for interpretation are 16 to $20=$ mild, 21 to $30=$ moderate, and $\geq 31$ = severe depressive symptoms.

Anxiety was assessed with the Multidimensional Anxiety Scale for Children (MASC) (18). The MASC is a self-report questionnaire of anxiety symptoms in children assessing symptoms in four basic scales including physical symptoms, harm avoidance, social anxiety and separation/panic, as well as a total anxiety scale score. The MASC uses T scores ( mean $=50, \mathrm{SD}=10$ ) that are presented according to age and sex.

Andrea completed a numerical rating scale to indicate current pain intensity on a scale from 0 (indicating 'no pain') to 10 (indicating 'worst pain imaginable'). Such rating scales are commonly used to assess pain intensity and have been shown to have good reliability and validity in pediatric populations $(8,19)$.

\section{RESULTS}

\section{Intensive outpatient pain rehabilitation}

Andrea and her family participated in a three-week, hospital-based outpatient interdisciplinary pediatric pain rehabilitation program aimed at helping adolescents with chronic pain learn coping skills to manage chronic symptoms to improve functioning. The program included physical therapy, occupational therapy, recreational therapy, biofeedback, cognitive behavioural therapy and parent education. The program occurs in a group setting with approximately 12 adolescents and young adults between 13 and 21 years of age. In this program, there is a significant amount of time dedicated to support and education of parents with $10 \mathrm{~h}$ to $15 \mathrm{~h}$ of parent programming each week.

By the time she had entered the program, Andrea had titrated off some medications as recommended by her physicians. She was using a cane to walk and wore sandals that would not exacerbate her foot and toe pain. During intake assessments, although oriented to time and place, Andrea was fatigued and fell asleep multiple times during consultation. Her mood was dysphoric and affect was flat. Her thought processes were tangential and content was appropriate to session. Her speech was slow and slurred. Eye contact was lacking at times because she had difficulty keeping her eyes open. Andrea and her mother reported being very motivated to decrease medications and learn coping skills to manage pain and return to regular functioning.

Andrea and her treatment team identified major lifestyle functional goals she would work on during treatment: independent performance of daily cares, walking independently, relaxing independently, eating regular meals, sleeping restfully/waking independently, regular school attendance, socialization with peers and medication tapering.

Throughout the course of her rehabilitation, Andrea was selfdirected and participated fully in all activities. However, before the start of medication tapering, Andrea expressed extreme anxiety. She was reluctant to stop many of her opioid medications for fear of pain

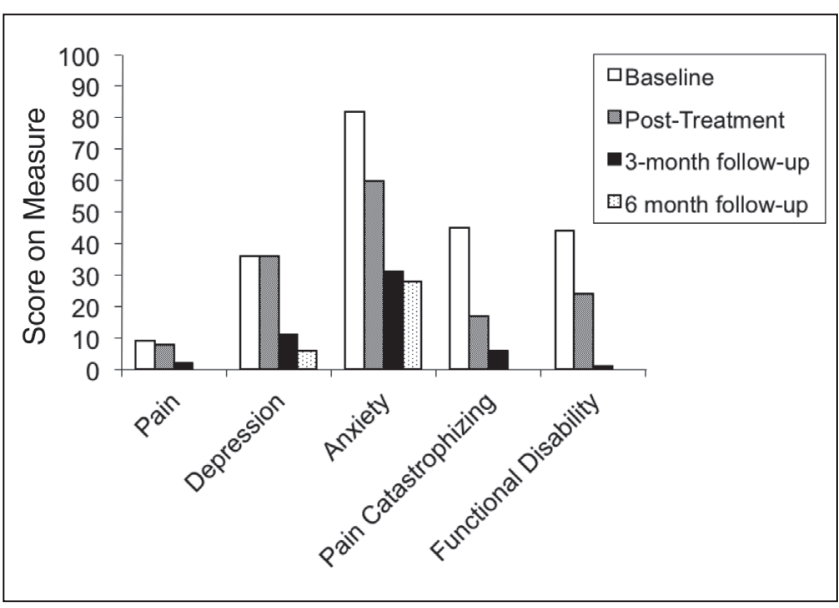

Figure 1) Outcome variables at four time points

exacerbation. She cried throughout consultations and was in clear emotional distress. However, she was gradually able to taper off all opioid medications including tapentadol, fentanyl patch and oxycodone, as well as sleep medications.

Her mental status gradually improved and she was more fully able to participate in daily programming and interactions with her peers. She worked at decreasing pain behaviours and cooperated with the treatment team. Within one week, she was able to walk without her cane. Initially, she had extreme difficulty with compliance with wearing socks and shoes due to allodynia. However, by the second week of therapy, she was able to wear shoes full time, in part as a result of the intensive physical therapy and desensitization that occurred on a daily basis as part of programming.

Andrea was asked to turn off her spinal cord stimulators for short periods of time and to use the coping strategies she was learning to manage any symptoms. Andrea complied, but experienced increased anxiety while doing so and was not able to discontinue use of the neurostimulators while in the three-week program. Nonetheless, she made drastic improvements in all five major lifestyle goals, and once again was able to function independently. She was encouraged to consider weaning off the neurostimulators at some point in the future when she believed her coping skills were more solidified.

In the parent program, Andrea's mother learned strategies to be supportive of her daughter while encouraging developmentally appropriate autonomy. She was asked to ignore pain behaviours and discontinue talking about symptoms with her daughter. She also developed a behaviour plan to provide incentives for progress and decreased privileges when Andrea demonstrated inappropriate behaviours such as being disrespectful toward parents, or missing school or other activities. Andrea's mother reported this aspect of the program was very helpful and she felt confident that she could return home and implement these strategies.

At the end of the program, Andrea reported clinically significant decreases in pain catastrophizing, anxiety and functional disability (Figure 1). At the six-month follow-up, she reported an absence of pain, pain catastrophizing and functional disability. Depression and anxiety symptoms were in the nonclinical range (Figure 1). She was also successfully titrated off all of her narcotic medications and most of her sleep medications by discharge and by three- and six-month follow-up (Table 1).

\section{One-year follow-up}

One year later, Andrea's mother telephoned the program staff to report that Andrea had continued to do well once returning home from the Pediatric Pain Rehabilitation Program. Andrea was attending school full time and was involved in a variety of extracurricular activities, 
including volleyball. She had returned to her normal weight. Eventually, Andrea decided the neurostimulators bothered her and decided to have them both removed, despite some hesitation from her medical providers at home due to concerns about relapse. Her mother reported that Andrea returned to her baseline level of functioning before pain onset and was now able to perform all of her activities of daily living.

\section{DISCUSSION}

The present case illustrates the devastating effects of chronic pain and how aggressive medical treatments may not provide adequate pain relief and may actually contribute to increased disability. The nature of Andrea's symptoms and her parents' desires to help their child led to intensive evaluation by multiple physicians to rule out the possibility of life-threatening disorders. When a specific diagnosis was eventually suggested, she attempted numerous medications and implantation of two spinal cord stimulators. Most importantly, her functioning and well-being did not improve but continued to decline with persistent pain, depression and the side effects of multiple drugs. Regardless of etiology, Andrea's pain developed into a chronic pain syndrome that involved severe disability. An interdisciplinary approach that included decreasing medications, physical reconditioning, and cognitive and behavioural therapy proved to be highly effective in decreasing anxiety, depression and disability for this patient.

The search for a definitive diagnosis in the setting of chronic pain The present case highlights the inherent difficulties of treating patients with chronic pain. Patients with chronic pain may feel frustrated and hopeless without a definitive diagnosis, and this may fuel further preoccupation with their pain. Patients often feel dissatisfied and/or invalidated when informed that multiple tests have not revealed a cause for their pain. They may then feel misunderstood and continue to search relentlessly for an answer and satisfactory treatment (20). They often believe providers are suggesting that their pain is 'not real' or is psychological in nature. In addition, because of the physical disability and depression that are often comorbid with chronic pain, patients and caretakers may often be even more desperate for an answer to resolve these issues. Thus, one of the greatest dangers occurs when desperate patients are driven to pursue drastic therapies in attempts to eliminate their pain.

For Andrea's parents, their well-intentioned concerns and their desire to find a cure for their daughter's pain led them on a time-consuming journey through doctors' offices and operating rooms. In their situation, it may have been reasonable to seek a second opinion, especially when the diagnosis was inconclusive and their daughter continued to experience significant pain. Their persistence may appear to have paid off when well-meaning physicians prescribed a new intervention that may have worked temporarily, only to relapse back into the cycle of continued pain and poor functioning. When one therapy did not work, they sought yet another treatment from another provider. In the end, these aggressive and experimental treatments accumulated and proved to be deleterious.

\section{Pain reduction versus functioning and well-being}

Many health care providers may define success in pain management as a reduction in pain score. Although this is certainly an appropriate target in the treatment of acute pain, targets for the treatment of chronic pain should also include improvement in functioning and overall well-being because complete pain relief may not be an attainable goal. More importantly, consuming preoccupation with pain relief may lead to years of searching for the next best treatment and avoidance of regular activities. Unfortunately, patients who decide to be home-schooled and stop activities that exacerbate their pain often experience increased pain and worsened functioning (7).

In the case of Andrea, it was likely the combination of her distress about her pain, her parents' concern about her well-being and her health care providers' desire to help her feel better that led to multiple medications that impacted her ability to function from a cognitive standpoint. The continued progression of her disability then led to unhealthy changes in the family dynamic, difficulty attending school, decreased participation in preferred activities and eventual isolation from same-age peers. All of this then contributed to Andrea struggling with self-esteem issues (self-efficacy about being able to perform most normal daily tasks), depression and suicidal ideation. By focusing primarily on the treatment of her pain, her health care providers may not have realized the negative effects this treatment was having on her overall functioning. Her treatment course appeared to have contributed to the transformation of a healthy and active 15-year-old girl into a minimally responsive, depressed and dysfunctional patient.

\section{Cognitive behavioural therapy, interdisciplinary approaches, and functional restoration}

Cognitive behavioural therapy and interdisciplinary approaches are the most widely accepted biopsychosocial treatments for chronic pain $(21,22)$. These treatments often do not focus on elimination of pain but on functional restoration (23). When compared with opioid and other medical treatments, cognitive behavioural therapy and interdisciplinary approaches not only yield comparable pain reduction rates, but are also more cost-effective and lead to significant increases in physical functionality, and reductions in future hospitalizations and surgeries $(22,24-27)$. In the pediatric population, it is particularly important to minimize this disruption in development by allowing children to return to school and to hopefully begin the process of normalizing their lives (28).

Given the utility of the biopsychosocial conceptualization and approach to chronic pain, we recommend health care providers consider interdisciplinary screening at initial assessment for all providers with chronic pain. In addition, at any point in the treatment of chronic pain where functioning starts to be adversely affected, an interdisciplinary treatment would likely be helpful. Moreover, patients tend to be more accepting of such an approach when providers emphasize that reported symptoms are real, but chronic pain has a complex etiology that requires treatment of the problem(s) from multiple angles.

Andrea's story highlights the importance of consideration of all aspects of a patient's well-being, including involvement in typical activities (eg, school), social interaction, family relationships and psychological well-being. Attempts at pain reduction should not be made without considering the possible effects on these other areas of functioning. Notably, in Andrea's case, we observed an improvement in functioning before an improvement in pain intensity. It is also important to note that an improvement in functioning without any improvement in pain intensity would have still been considered a treatment success.

\section{CONCLUSION}

Although Andrea's case is an extreme example, her experiences of spending years seeking a satisfactory medical diagnosis and treatment to eliminate pain, and progressive disability in multiple areas of functioning mirror that of many adolescents who experience chronic pain. Fortunately, Andrea was ultimately referred to an interdisciplinary treatment program that encouraged her to discontinue medications causing side effects and helped her and her family learn and implement strategies of increased coping in the context of pain and reconceptualizing the treatment goal to be fullly functioning. For the millions of individuals experiencing chronic pain, it is imperative to have discussions about comprehensive approaches to pain management and the importance of including quality of life and overall functioning as treatment goals, which are just as important, if not more so, as alleviating the pain itself.

\section{DISCLOSURES: None.}




\section{REFERENCES}

1. van Tilburg MA, Spence NJ, Whitehead WE, Bangdiwala S, Goldston DB. Chronic pain in adolescents is associated with suicidal thoughts and behaviors. J Pain 2011;12:1032-9.

2. Gaskin DJ, Richard P. The economic costs of pain in the United States. J Pain 2012;13:715-24.

3. Sleed M, Eccleston C, Beecham J, Knapp M, Jordan A. The economic impact of chronic pain in adolescence: Methodological considerations and a preliminary costs-of-illness study. Pain 2005;119:183-90.

4. Eccleston C, Malleson P. Managing chronic pain in children and adolescents. We need to address the embarrassing lack of data for this common problem. BMJ 2003;326:1408-9.

5. Lachapelle DL, Lavoie S, Boudreau A. The meaning and process of pain acceptance. Perceptions of women living with arthritis and fibromyalgia. Pain Res Manag 2008;13:201-10.

6. Gatchel RJ, Peng YB, Peters ML, Fuchs PN, Turk DC. The biopsychosocial approach to chronic pain: Scientific advances and future directions. Psychol Bull 2007;133:581-624.

7. Zernikow B, Wager J, Hechler T, et al. Characteristics of highly impaired children with severe chronic pain: A 5-year retrospective study on 2249 pediatric pain patients. BMC Pediatr 2012;12:54.

8. Miro J, Castarlenas E, Huguet A. Evidence for the use of a numerical rating scale to assess the intensity of pediatric pain. Eur J Pain 2009;13:1089-95.

9. Walker LS, Greene JW. The functional disability inventory: Measuring a neglected dimension of child health status. J Pediatr Psychol 1991;16:39-58.

10. Kashikar-Zuck S, Flowers SR, Claar RL, et al. Clinical utility and validity of the Functional Disability Inventory among a multicenter sample of youth with chronic pain. Pain 2011;152:1600-7.

11. Claar RL, Walker LS. Functional assessment of pediatric pain patients: Psychometric properties of the functional disability inventory. Pain 2006;121:77-84

12. Gauntlett-Gilbert J, Eccleston C. Disability in adolescents with chronic pain: Patterns and predictors across different domains of functioning. Pain 2007;131:132-141.

13. Crombez G, Bijttebier P, Eccleston C, et al. The child version of the Pain Catastrophizing Scale (PCS-C): A preliminary validation. Pain 2003;104:639-46.

14. Vervoort T, Eccleston C, Goubert L, Buysse A, Crombez G. Children's catastrophic thinking about their pain predicts pain and disability 6 months later. Eur J Pain 2010;14:90-6.

15. Weissman MM, Orvaschel H, Padian N. Children's symptom and social functioning self-report scales. Comparison of mothers' and children's reports. J Nerv Mental Dis 1980;168:736-40.
16. Faulstich ME, Carey MP, Ruggiero L, Enyart P, Gresham F. Assessment of depression in childhood and adolescence: An evaluation of the Center for Epidemiological Studies Depression Scale for Children (CES-DC). Am J Psychiatr 1986;143:1024-7.

17. Roberts RE, Andrews JA, Lewinsohn PM, Hops H. Assessment of depression in adolescents using the Center for Epidemiologic Studies Depression Scale. Psychol Assess 1990;2:122-8.

18. March JS, Parker JD, Sullivan K, Stallings P, Conners CK. The Multidimensional Anxiety Scale for Children (MASC): Factor structure, reliability, and validity. J Am Acad Child Adolesc Psychiatry 1997;36:554-65.

19. von Baeyer CL, Spagrud LJ, McCormick JC, Choo E, Neville K, Connelly MA. Three new datasets supporting use of the Numerical Rating Scale (NRS-11) for children's self-reports of pain intensity. Pain 2009;143:223-7.

20. van Wilgen CP, Keizer D. The sensitization model to explain how chronic pain exists without tissue damage. Pain Manage Nurs 2012;13:60-5.

21. Day MA, Thorn BE, Burns JW. The continuing evolution of biopsychosocial interventions for chronic pain. J Cog Psychother 2012;26:114-29.

22. Turk DC, Loeser JD, Monarch ES. Chronic pain: Purposes and costs of interdisciplinary pain rehabilitation programs. Trends EvidenceBased Neuropsychiatr 2002;4:64-9.

23. Gatchel RJ, Okifuji A. Evidence-based scientific data documenting the treatment and cost-effectiveness of comprehensive pain programs for chronic nonmalignant pain. J Pain 2006;7:779-93.

24. Flor H, Fydrich T, Turk DC. Efficacy of metadisciplinary pain treatment centers: A meta-analytic flow. Pain 1992;49:221-30.

25. Caudill M, Schnable R, Zuttermeister P, Benson H, Friedman R. Decreased clinic use by chronic pain patients: Response to behavioral medicine intervention. Clin J Pain 1991;7:305-10.

26. Simmons JW, Avant WS, Demski J, Parisher D. Determining successful pain clinic treatment through validation of costeffectiveness. Spine J 1988;13:342-4.

27. Townsend CO, Kerkvliet JL, Bruce BK, et al. A longitudinal study of the efficacy of a comprehensive pain rehabilitation program with opioid withdrawal: Comparison of treatment outcomes based on opioid use status at admission. Pain 2008;140:177-89.

28. Carter BD, Threlkeld BM. Psychosocial perspectives in the treatment of pediatric chronic pain. Pediatr Rheum Online J 2012;10:15. 


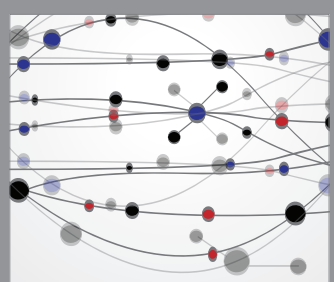

The Scientific World Journal
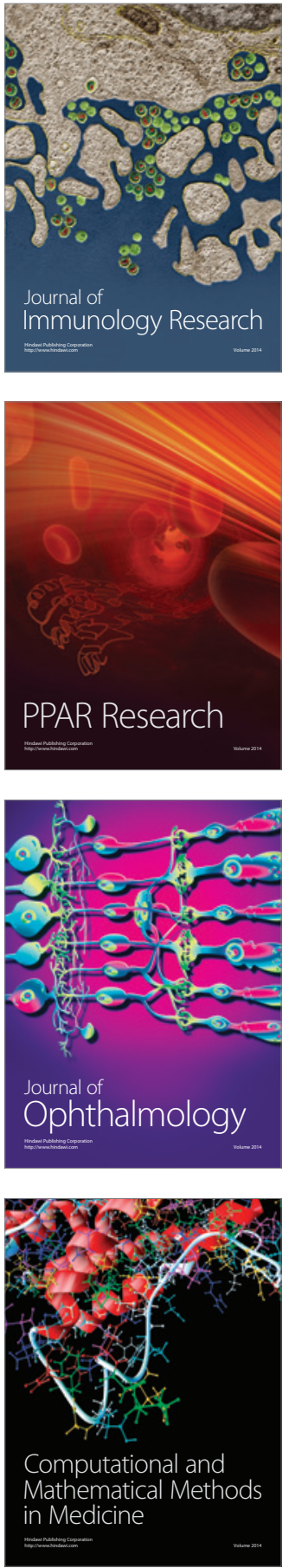

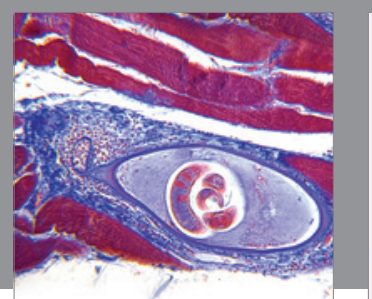

Gastroenterology Research and Practice

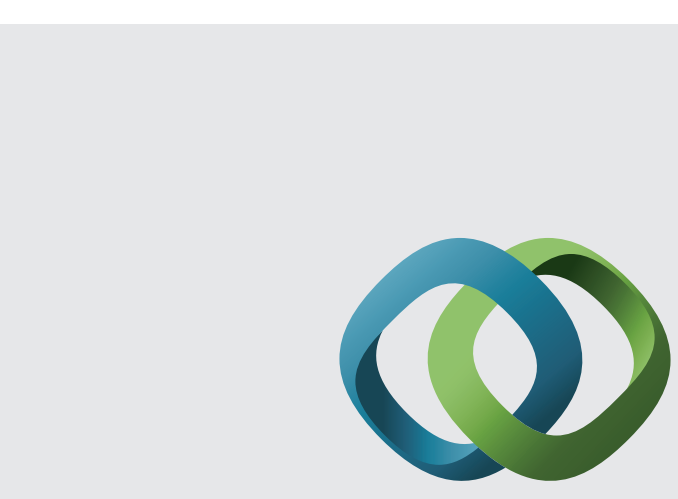

\section{Hindawi}

Submit your manuscripts at

http://www.hindawi.com
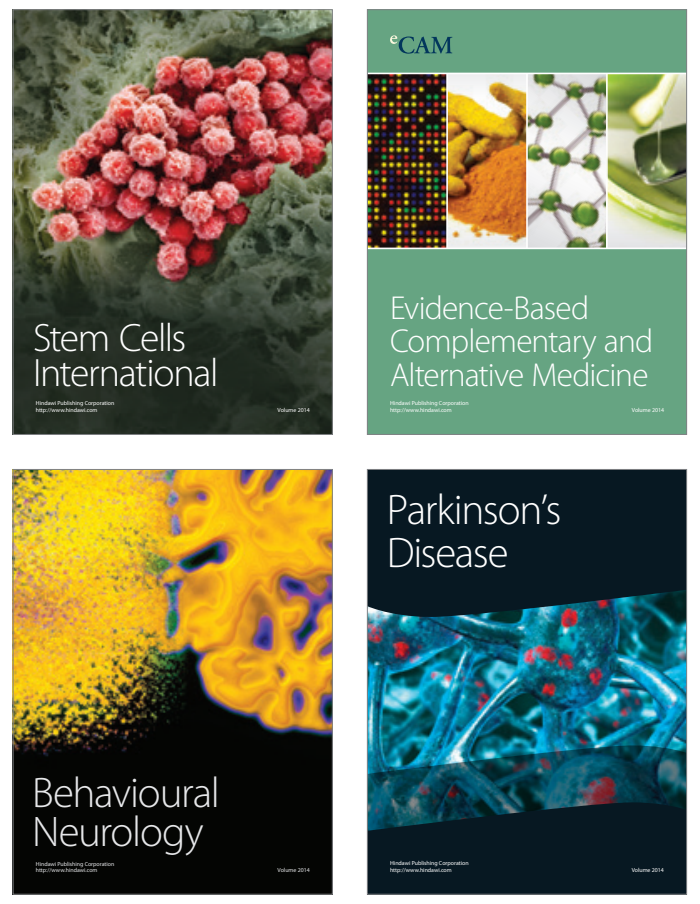
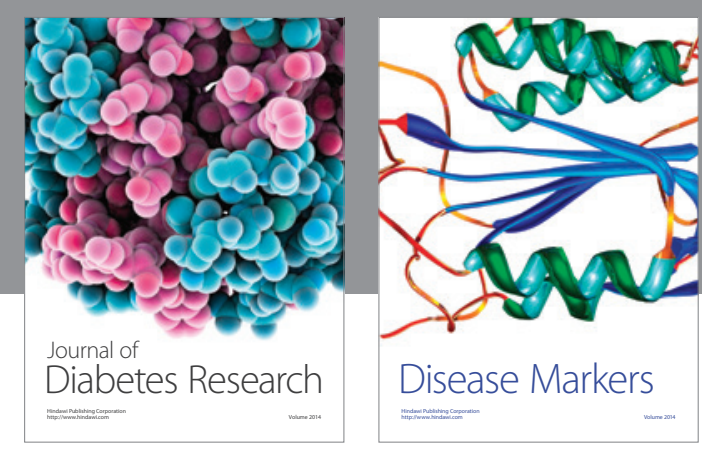

Disease Markers
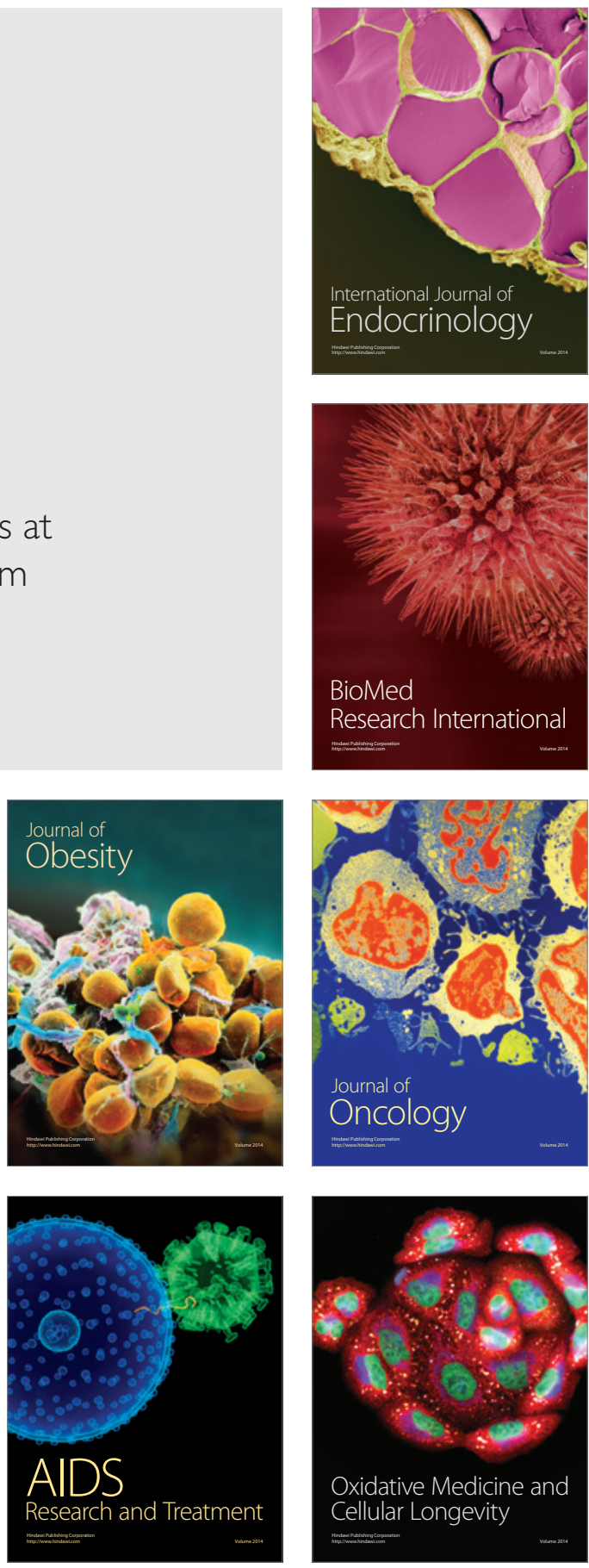